\title{
APONTAMENTOS ACERCA DO SIGNFICADO DE CIDADANIA E DA FORMAÇÃO DO CIDADÃO NA PERSPECTIVA DE PAULO FREIRE E MILTON SANTOS
}

\author{
Claudete Robalos da Cruz ${ }^{1}$ \\ Gomercindo Ghiggi ${ }^{2}$
}

\section{Resumo:}

O presente artigo tem a intenção de apontar, a partir dos avanços e retrocessos dos processos sociais e culturais da construção da cidadania, reflexões em torno do significado de cidadania e da formação do cidadão contemporâneo na perspectiva de Paulo Freire e Milton Santos.

Palavras-chaves: Cidadania, Sociedade, Formação Cultural.

\begin{abstract}
:
The present paper intends to point out, from advances and setbacks of social and cultural processes of the citizenship building, reflections concerning the meaning of citizenship and of the contemporary citizen education based on the views of Paulo Freire and Milton Santos.
\end{abstract}

Keywords: Citizenship; Society; Cultural Education

\section{Introdução}

A palavra cidadania geralmente é utilizada para expressar os direitos e os deveres dos indivíduos. Tais Direitos estão assegurados por leis e princípios, tais como Constituição Federal, Estatutos, leis trabalhistas, Direitos Humanos, em demais leis que garantem os direitos do cidadão, no entanto, a experiência diária mostra que, ainda prevalece os privilégios, o não cumprimento de leis, injustiças com a grande maioria da população; Aliado a esse quadro, tem-se uma visão mercantilista acerca do que significa ser cidadão, que na visão mercadológica, significa ser consumidor. Na tentativa de tornarse um consumidor-cidadão busca-se essa inserção social por meio do consumo, ostentação de bens materiais, em que a marca evidencia o poder aquisitivo do

\footnotetext{
${ }^{1}$ Doutoranda em Educação pela UFPel - cruzufpel@gmail.com, Bolsista CAPES.

${ }^{2}$ Professor Dr. do Programa de Pós-Graduação em Educação da UFPel - gghiggi@ terra.com.br
} 
consumidor e seu status social. Disso resulta o aumento dos assaltos, a delinquência infantil e juvenil, prostituição, criminalidade, assassinatos, tráfico e uso de drogas, corrupção, desemprego, que apesar do aumento dos programas de ordem social e ações visando à melhoria das condições de vida do povo brasileiro, ainda assim, questiona-se acerca exercício da cidadania. Diante desse cenário, recorreu-se a Paulo Freire e Milton Santos para compreender-se o que significa ser cidadão e qual o verdadeiro sentido da cidadania nos tempos atuais.

\section{Reflexões em torno do Conceito de Cidadania: avanços e retrocessos}

A origem da cidadania esta ligada ao desenvolvimento da polis grega, entre os séculos VIII e VII a.C. Os gregos, que eram pastores nômades, a partir do aprimoramento técnicas de agricultura e pecuária, foram se fixando em alguns locais, iniciando assim as cidades que chamavam de polis (cidades-estado na Grécia antiga). Cada cidade possuía autonomia política e administrativa, pois cada uma fazia suas próprias leis, as quais só tinham validade em determinada polis. Para eles, política era o envolvimento que o indivíduo tinha com a administração da polis. Quando era apenas uma pessoa quem governava, tinha-se a monarquia, por outro lado, se a polis era administrada por um grupo de pessoas, tinha-se a aristocracia.

Segundo Manzini-Covre (1986), Clístenes no ano 500 a.C., legislador de Atenas, realizou mudanças na administração das cidades, dividindo a cidade em unidades, "demos", onde criou as Assembleias, para aprovar as leis. Assim, todos os cidadãos participavam na administração da polis. Daí se originou a democracia, que significa governo dos demos. Como as decisões acerca da polis eram tomadas em Assembleias, exigia-se participação dos homem livres. Todavia, importante ressaltar como aponta Manzini-Covre (1986, p. 19): "não faziam parte dos homens livres, as mulheres, as crianças, os escravos, e os estrangeiros, os quais não tinham direito a participação política, apesar de serem a maioria, cerca de noventa por cento da população.”

No período do desenvolvimento da sociedade feudal, entre o século V e XII, houve um retrocesso nas questões ligadas a cidadania. A sociedade feudal, caracterizada pela propriedade rural, na qual, os servos e camponeses viviam submetidos aos desejos do senhor feudal. Nesse contexto social, não havia a possibilidade de mudança de classe social, por exemplo, quem nascia servo, seria a vida toda servo. Com o desenvolvimento da sociedade capitalista, século XV, com a ascensão da burguesia em

\begin{tabular}{|l|l|l|l|l|}
\hline Revista Dialectus & Ano 1 & n. 2 & Janeiro-Junho 2013 & p. 195-210 \\
\hline
\end{tabular}


luta contra o feudalismo, o exercício da cidadania foi retomado, "com o homem do burgo, o burguês, nascia o cidadão, o homem do trabalho livre, vivendo num lugar livre, a cidade" (SANTOS, 2002, p. 9). Neste período, proclamaram-se as Cartas Constitucionais, as quais estabeleciam direitos iguais a todos e a valorizando o cidadão. A burguesia estabeleceu os três poderes: o executivo, legislativo e judiciário. Nesta forma de administração pública, o Estado era governado pelas leis que estabeleciam os direitos e deveres do cidadão. A democracia passa a ser representativa, e através do processo de eleição, os cidadãos escolhem seus representantes para administrar sua cidade, estado ou país (cf. MANZINI-COVRE, 1986).

A cidadania é uma construção dos homens decorrentes de suas relações sociais estabelecidas no decorrer dos tempos. Ela evolui através de processos de lutas e reivindicações sociais. De acordo com Santos, esse processo de evolução e conquistas levou a condição de "membro da sociedade nacional" no século XVII, ao "direito de associação" no século XIX, até serem alcançados os "direitos sociais "em pleno século XX” (SANTOS, 2002, p. 9).

Observa-se que a construção da cidadania, ou seja, sua representação efetiva do significado, não ocorreu de modo linear, mas aconteceu mediante avanços e retrocessos. No decorrer da história, surgiram às leis com o intuito de regulamentar, estabelecer limites e apontar direitos e os deveres dos cidadãos, no sentido de organizar a vida em sociedade. Assim, foram se consolidando os princípios de cidadania através das leis, declarações e movimentos sociais engajados na luta pela melhoria de suas condições de vida. A Declaração dos Direitos Humanos, por exemplo, foi uma reação as atrocidades praticadas durante a Segunda Guerra Mundial. Decorrente ao impacto causado pelo holocausto buscou-se estabelecer um fundamento ético para mediar à relação dos Estados com seus cidadãos. Daí em diante, a classe trabalhadora ganha um espaço para suas reivindicações, com o surgimento dos sindicatos e grupos organizados (cf. THOMAZ, 2008).

No Brasil não teve a transição do feudalismo para o capitalismo, por conta da exploração de Portugal e depois da Inglaterra, a história do país se inicia já sobre a dominação capitalista. Resultando na ascensão do poder de uma elite econômica e política que possuíam regalias e privilégios, e dominação e submissão da maioria da população brasileira, que sobreviveram em situação de miséria e pobreza. Todavia, Thomaz aponta que "com a imigração italiana que a luta por igualdade teve início" 
(THOMAZ, 2008, p. 5). E a partir dos anos de 1910 e 1920 aconteceram as lutas operárias, visando a melhoria das condições de vida dos operários.

No entanto, nos anos de 1964 a 1985, houve um retrocesso na luta pela cidadania, uma vez que, após o golpe militar, a população viveu neste período uma 'anticidadania', quando os brasileiros eram torturados, presos, exilados e mesmos mortos (MANZINICOVRE, 1986). Nesse período, concorda-se com Santos (2002) que

\begin{abstract}
o modelo econômico que conduziu ao chamado "milagre econômico" vai buscar suas raízes nos mesmos postulados que levaram à supressão das liberdades civis, acusadas então como um fermento deletério, capaz de levar o país à anarquia. Trata-se também, de um modelo político e social, tanto responsável pela eliminação do embrião de cidadania que então se desenvolvia, como pela opção de alargamento de uma nova classe média em detrimento da massa de pobres que o "milagre" não apenas deixou de suprimir, como também aumentou.
\end{abstract}

Contra esse cenário social e político que se instalou, emergiu o Movimento Operário Brasileiro, que lutaram contra a ditadura militar e manifestando seus descontentamentos com a situação econômica, política e social do país, através de greves, principalmente nos anos de 1978 e 1979. Tal participação popular foi de grande importância para o avanço da cidadania no país, pois

\begin{abstract}
o caráter massivo e pacífico das greves deixou perplexa a ditadura militar em sua fase terminal. Sem ter como reprimir a ofensiva operária iniciada em $12 \mathrm{de}$ maio na Scania (e que logo se alastrou por todo o país), o regime em crise, assistia à sua lei de antigreve ser revogada pela prática de uma classe que, finalmente, recobrava a sua capacidade de luta e projetava nacionalmente a liderança de Lula [...] Mas não foi só a ditadura a ser surpreendida: a própria esquerda deparou com um vigoroso movimento de massas espontâneo que, inicialmente, era hostil a todos os partidos políticos existentes, e cuja liderança declarava-se 'sem ideologia'. (FREDERICO apud LOPES, 2005, p. 4).
\end{abstract}

Em 1979 com a promulgação da Lei da Reforma Partidária, abriu espaço para que em 1980, surgisse no bojo deste movimento, o Partido dos Trabalhadores - PT, que

\footnotetext{
nasce da vontade de independência política dos trabalhadores, já cansados de servir de massa de manobra para os políticos e os partidos comprometidos com a manutenção da atual ordem econômica, social e política. Nasce, portanto, da vontade de emancipação das massas populares. Os trabalhadores já sabem que a liberdade nunca foi nem será dada de presente, mas será obra do próprio esforço coletivo. Por isso protestam quando, uma vez mais na história brasileira, veem os partidos sendo formados de cima para baixo, do estado para a sociedade, dos exploradores para os explorados (PARTIDO DOS TRABALHADORES apud LOPES, 2005, p .4).
}

Ao mesmo tempo, enquanto avançava a luta operária nos centros industriais e nas diversas cidades, com manifestação dos movimentos populares por moradia, saúde, avançava também o movimento dos trabalhadores no campo, por melhoria das 
condições da vida rural, pelo fim do latifúndio, emergiu assim o Movimento dos Trabalhadores Sem Terra - MST, instituído em janeiro de 1984 (LOPES, 2005).

No ano seguinte, iniciava o movimento que ficou conhecido como "Diretas Jâ" teve a participação em massa dos brasileiros, que aconteceu em 1985, exigindo a eleição direta para a Presidência do país. Com a eleição de Tancredo Neves para Presidente do Brasil, acaba a ditadura, resultando promulgação da Constituinte e da Constituição da República de1988.

Outro momento de grande participação popular foi em 1992, quando o movimento “caras-pintadas", formado por estudantes brasileiros, pintados de cores verde e amarelo, saíram às ruas, pedindo o afastamento do Presidente Fernando Collor de Melo por estar envolvido em corrupção. A mobilização popular foi tão intensa que o Congresso aprovou o Impeachment. Conforme Lopes "este foi, no entanto, o último grande movimento de massa, desde os movimentos do $\mathrm{ABC}$ paulista, passando pela luta pelas diretas já e os movimentos em torno da constituinte." (LOPES, 2005, p.5).

O sucessor do mandato de Collor, completado por Itamar Franco, foi Fernando Henrique Cardoso. Em seus oito anos de mandato, $1^{\circ}$ mandato (1994-1997) e $2^{\circ}$ mandato (1998-2002), Fernando Henrique Cardoso, implantou e consolidou o projeto neoliberal no país, com o desenvolvimento do Plano Real e privatização de diversas estatais. Segundo Lopes (2005, p. 5)

\begin{abstract}
com a chamada Reforma do Estado e a privatização das empresas e de grande parte dos serviços do Estado, o governo assegurou as condições de controle absoluto, pelo capital, do processo de reestruturação do capitalismo e da relação capital/trabalho que, com a flexibilização e a precarização do trabalho, atuam com eficácia na subjetividade de toda a vida social e, de modo especial, da classe trabalhadora.
\end{abstract}

Desse período em diante, coube ao Movimento dos Trabalhadores Rurais manifestarem-se contra as políticas neoliberais, através da luta pela terra, por meio de diversas ocupações e marchas em favor dos direitos sociais do povo brasileiro. E em 2002, nas eleições presidências, os brasileiros manifestaram sua contestação ao projeto neoliberal. De acordo com Lopes “A eleição de Luís Inácio da Silva e do PT expressou uma resposta e abriu uma oportunidade de contribuição efetiva na construção do projeto emancipador da classe trabalhadora e da sociedade brasileira" (Ibidem, p. 7).

Contudo, não se pode dizer que houve um avanço na cidadania, o então, presidente do povo, "foi colocar-se a tarefa de administração dos interesses do capital" (Ibidem). 
Concorda-se com Milton Santos, quando expõe em síntese sua crítica ao processo de elaboração da democracia em nosso país, assim afirma:

\begin{abstract}
em nenhum outro país foram assim contemporâneos e concomitantes processos como a desruralização, as migrações brutais desenraizadoras, a urbanização galopante e concentradora, a expansão do consumo de massa, o crescimento econômico delirante, a concentração da mídia escrita, falada e televisionada, a degradação das escolas, a instalação de um regime repressivo com a supressão dos direitos elementares dos indivíduos, a substituição rápida e brutal, o triunfo, ainda que superficial, de uma filosofia de vida que privilegia os meios materiais e se despreocupa com os aspectos finalistas da existência e entroniza o egoísmo como lei superior, porque é o instrumento da buscada ascensão social. Em lugar do cidadão formou-se um consumidor, que aceita ser chamado de usuário. (SANTOS, 2002, p.12)
\end{abstract}

Tal contexto, aliado a um modelo de ensino tradicional, em que predominou o caráter informativo, limitando ao desenvolvimento de habilidades necessárias a realização dos exames avaliativos, configuraram uma escola seletiva menosprezando as diferenças individuais, cabendo ao aluno adaptar-se ao sistema de ensino, contribuindo para ampliar as desigualdades sociais no país.

Conforme Santos (2002, p. 42):

a educação corrente e formal, simplificadora das realidades do mundo, subordinada à lógica dos negócios, subserviente às noções de sucesso, ensina um humanismo sem coragem, mais destinado a ser um corpo de doutrina independente do mundo real que nos cerca, condenado a ser um humanismo silente, ultrapassado, incapaz de atingir uma visão sintética das coisas que existem, quando o humanismo verdadeiro tem de ser constantemente renovado, para não ser conformista e poder dar resposta às aspirações efetivas da sociedade, necessárias ao trabalho permanente de recomposição do homem livre, para que ele se ponha à altura do seu tempo histórico.

Todavia, constata-se em nosso cotidiano, seja através da mídia, violência de toda ordem: corrupção, assassinatos, assaltos, prostituição, tráfico de drogas, de pessoas, de órgãos, de animais, etc. Como salienta Thomaz (2008, p. 12):

\begin{abstract}
continua-se a ver crianças pedindo esmolas nas ruas da cidade, quando as mesmas deveriam estar estudando, crescendo sadiamente, sendo bem alimentada, tendo um lar, sendo que isso lhes é garantido pela Declaração dos Direitos da Criança, aprovada pela Organização das Nações Unidas (ONU) em 1959 e reforçado no Brasil pelo Estatuto da Criança e do Adolescente (ECA) - Lei ${ }^{\circ} 8.069 / 90$.
\end{abstract}

Tal conjuntura expressa à falta de cidadania, de consciência social e política, seja por parte dos políticos como da população em geral. Como bem sintetiza Dimenstein $(1999$, p. 33) que

um menino de rua é mais do que um ser descalço, magro, ameaçador e mal vestido. É a prova da carência de cidadania de todo um país, em que uma imensa quantidade de garantias não saiu do papel da Constituição. É um espelho ambulante da História do Brasil. 
Concorda-se com Santos (2002) o progresso material que conhecemos hoje em nosso país, foi resultado da aceitação extrema da racionalidade econômica, exercidas pelas firmas estrangeiras e nacionais, as quais foram tomando lugar das instituições governamentais, impondo seus interesses e suas ideologias como essenciais para o desenvolvimento do país, e nisso "a noção de direitos políticos e de direitos indivíduos teve que ser desrespeitada, se não frequentemente pisoteada e anulada" (SANTOS, 2002, p. 3). Nesse sentido, "o modelo político e o modelo cívico foram instrumentais ao modelo econômico" (Ibidem), quando deveria ser o contrário, como afirma posteriormente: "numa democracia verdadeira, é o modelo econômico que se subordina ao modelo cívico (Ibidem, p. 5). Devemos partir do cidadão para a economia e não da economia para o cidadão". Decorrente a construção de um modelo cívico que teve como meta transformar o indivíduo em consumidor, ao invés do cidadão. Como afirma Santos "numa sociedade tornada competitiva pelos valores que erigiu como dogmas, o consumo é o verdadeiro ópio, cujos templos modernos são os Shoppings Centers e os supermercados, aliás construídos à feição das catedrais (Ibidem, p. 34). Tal modelo fortaleceu-se com "a propaganda como fazedora de símbolos, o consumismo como seu portador, a cultura de massas como caldo de cultura fabricado, a burocracia como instrumento e fonte de alienação”( Ibidem, p. 11). Diante disso, foi suprimida a defesa do direito ao trabalho e a remuneração digna, à saúde, a educação, a saneamento básico, ao direito de bens vitais mínimos para se viver com dignidade.

No atual contexto social, as pessoas são levadas a considerar-se excluídas quando não se vêem como potencial consumidor de produtos e serviços em voga, tem- se uma cidadania regulada, em que os direitos dos cidadãos são resultante dos direitos das suas profissões e ocupações. Nas palavras de Wanderley Guilherme Santos "a cidadania está embutida na profissão e os direitos do cidadão restringem-se aos direitos do lugar que ocupa no processo produtivo, tal como reconhecido em lei. Tornam-se pré- cidadãos, assim, todos aqueles cuja ocupação a lei desconhece" (SANTOS, 1979, p. 75). Tal afirmação torna-se evidente na realidade vivida pela sociedade baseada nos princípios consumistas, porque, dependendo da profissão, da ocupação, há variações no poder aquisitivo e assim como no acesso aos direitos sociais e políticos. Daí há cidadania e cidadanias, segundo Santos (2002, p. 12): “nos países subdesenvolvidos de um modo geral há cidadãos de classes diversas, há os que são mais cidadãos, os que são menos cidadãos e os que nem mesmo ainda o são". A capacidade de manipulação construída pela sociedade de consumo é tão forte, que a exclusão das pessoas aos 
shoppings centers, a moda, e demais bens materiais coloca as pessoas a condição de alienados, além de incorporam um aprendizado do consumo tão profundo, que dificulta as pessoas distinguirem as aspirações pessoais legitimas, das impostas pelo sistema econômico e político. O consumo desenfreado contribui para o "aniquilamento da personalidade", impedindo que os indivíduos assumam-se como sujeitos históricos. Diante desse quadro, emerge de acordo com Santos (2002, p. 17):

\begin{abstract}
o consumidor insatisfeito e, por isso, votado a permanecer consumidor. Sua dependência em relação aos novos objetos limita sua vocação para obter uma individualidade e reduz a possibilidade dos encontros interpessoais diretos e enriquecedores, porque simbólicos em sua própria origem. A comunicação entre as pessoas é frequentemente intermediada por coisas, tendo uma lógica mais instrumental que existencial.
\end{abstract}

E acrescenta: “a força da alienação vem dessa fragilidade dos indivíduos, quando apenas conseguem identificar o que os separa e não o que os une" (Ibidem). Tal quadro de vida infelizmente torna-nos joguetes no curso da vida coletiva, como salienta Santos "a existência é vivida não tanto para a consagração dos valores, mas para a busca das coisas, o produtor se tornando submisso ao objeto produzido."(Ibidem, p. 37). Do mesmo modo, as relações pessoais passaram a ser mediadas por interesses econômicos, de tal modo que o produto, o lucro tem maior valor e relevância do que os valores humanos. Santos considera que com "a glorificação do consumo se acompanha a diminuição gradativa de outras sensibilidades, como a noção de individualidade que, aliás, constitui um dos alicerces da cidadania" (Ibidem, p. 35). O consumo atualmente, se reveste de diferentes formas, e o aniquilamento da cidadania ocorre de várias maneiras. Santos alerta que (Ibidem, p. 41):

o consumidor não é o cidadão. Nem o consumidor de bens materiais, ilusões tornadas realidades como símbolos: a casa própria, o automóvel, os objetos, as coisas que dão status. Nem o consumidor de bens imateriais ou culturais, regalias de um consumo elitizado como o turismo e as viagens, os clubes e as diversões pagas; ou de bens conquistados para participar ainda mais do consumo, como a educação profissional, pseudo-educação que não conduz ao entendimento do mundo.

$\mathrm{Na}$ mesma direção Freire destaca que "nesta ânsia irrefreada de posse, desenvolvem em si a convicção de que lhes é possível transformar tudo a seu poder de compra. Daí sua concepção estritamente materialista da existência. O dinheiro é a medida de todas as coisas. E o lucro, seu objetivo principal" (FREIRE, 1987, p. 46). Tal comportamento gera a autodesvalia, que se trata da introjeção que fazem os oprimidos a partir do discurso dominante. De tanto, escutar que o poder de compra é o que garante sua inserção na sociedade, acabam por acreditar que são incapazes de conseguir acesso

\begin{tabular}{|l|l|l|l|l|} 
Revista Dialectus & Ano 1 & n. 2 & Janeiro-Junho 2013 & p. 195-210 \\
\hline
\end{tabular}


a tais bens e consideram-se, portanto, excluídos, sem valor, sem dignidade; tantos outros irão buscar a qualquer custo, meios para inserir nessa lógica capitalista, seja através do tráfico, prostituição, etc. Nesse sentido, é possível constatar que, “a própria existência vivida mostra a cada qual que o espaço em que vivemos é, na realidade, um espaço sem cidadãos" (SANTOS, 2002, p. 48), pois, enquanto manter essa lógica, teremos de um lado, pessoas correndo em busca de acesso a tais bens, outros usufruindo, outros sem acesso nenhum. E pensar, refletir, analisar sobre as condições de vida, sobre os fundamentos da sociedade, poucos fizeram e poucos fazem.

\section{O Significado da Cidadania e da Formação do Cidadão para Paulo Freire e Milton Santos}

Diante de um contexto negador de cidadania e falta de participação política, Paulo Freire e Milton Santos, engajaram-se na busca por uma sociedade mais justa e mais solidária. Concomitantemente ao fervor desenvolvimentista, nos anos de 1959 a 1963, ocorreu no Brasil movimentos educativos que se colocavam contra aos processos de massificação da sociedade, dentre eles destaca a pedagogia de Paulo Freire. De acordo com Brandão (apud BEZERRA, 1980, p. 43):

É possível dizer que tanto Paulo Freire quanto o MEB procuraram transformar uma educação fundamental para o povo (os valores políticos dos grupos externos retraduzidos na linguagem de ajuda ao povo) em uma educação do povo (os valores culturais dos grupos populares retraduzidos através da educação levada a eles).

Os movimentos de educação popular emergiram a favor da conscientização, de uma educação comprometida com os interesses dos sujeitos envolvidos, com a formação do cidadão. Dentre os diversos exemplos, do engajamento de Freire na busca da efetivação dos direitos sociais e humanos dos indivíduos, destacam-se as práticas educativas de Angicos/RN, no início da década de 1960. No exílio, sua pedagogia avança para outros países e continentes. Freire participa de processos de alfabetização, politização e em nome da constituição de uma democracia radical na África, Ásia, Europa e América.

Freire direcionou seu trabalho pedagógico, principalmente aos excluídos das ações políticas. Assim de dedica o livro Pedagogia do Oprimido "aos esfarrapados do mundo e aos que neles se descobrem e, assim descobrindo-se, com eles sofrem, mas, sobretudo, com eles lutam" (FREIRE, 1987, p. 23). Nas suas viagens pelo mundo, defendeu uma pedagogia política centrada na liberdade e na autonomia do ser, propondo

\begin{tabular}{|l|l|l|l|l|} 
Revista Dialectus & Ano 1 & n. 2 & Janeiro-Junho 2013 & p. 195-210 \\
\hline
\end{tabular}


a politização da educação. Direcionou sua ação educativa, em busca da assunção do indivíduo tratado como objeto para condição de sujeito, fazedor de cultura e da história, chamou-os a assumirem-se e lutarem pelos seus direitos sociais e políticos. Orientou-os para viverem coerentes com sua vocação ontológica, a de seres humanos em busca de sua humanização e com seus projetos. Tanto que, como

\begin{abstract}
seres históricos, inseridos no tempo e não imersos nele, os seres humanos se movem no mundo, capazes de optar, de decidir, de valorar. Têm o sentido do projeto, em contrasta e com os outros animais, mesmo quando estes vão além de uma rotina puramente instintiva. Daí que a ação humana, ingênua ou crítica, envolva finalidades, sem o que não seria práxis, ainda que fosse orientação no mundo. E não sendo práxis seria ação que ignoraria seu próprio processo e seus objetivos. A relação entre a consciência do projeto proposto e o processo no qual se busca sua concretização é a base da ação planificada dos seres humanos, que implica em métodos, objetivos e opções de valor. (FREIRE, 1978, p. 43)
\end{abstract}

Freire esclarece que toda a ação educativa, seja ela ingênua ou crítica, desenvolvese a fim de efetivar um projeto educativo, social, político, econômico ou cultural. Para sua concretização implica escolha de métodos e opções valorativas. Daí porque ao conceber sua pedagogia como problematizadora da realidade e dos projetos vigentes, aponta nas suas diversas obras e escritos, alguns princípios e modos de ser indispensáveis a práxis educativa progressista, assim destaca Freire (1996, p. 46) que

\begin{abstract}
uma das tarefas mais importantes da prática educativo-crítica é propiciar as condições em que os educandos em suas relações uns com os outros e todos com o professor ou com a professora ensaiam a experiência profunda de assumir-se. Assumir-se como ser social e histórico, como ser pensante, comunicante, transformador, criador, realizador de sonhos, capaz de ter raiva porque capaz de amar. Assumir-se como sujeito porque capaz de reconhecerse como objeto.
\end{abstract}

A educação, segundo Freire, deve servir ao desvelamento das situações opressoras. Daí necessariamente, seu método de aprendizagem, toma a realidade concreta como ponto de partida, porque considera que a educação deve tornar-se instrumento de humanização, ou seja, por meio do processo de conscientização, os sujeitos ampliam suas percepções e tornam-se capazes de denunciar as desumanizações e anunciar processos humanizadores. Observa-se que, os objetivos e as finalidades, dessa perspectiva de ensino e aprendizagem, se reveste em um ato político comprometido com a transformação social e com a formação do sujeito histórico. Para Paulo Freire, cidadão significa "indivíduo no gozo dos direitos civis e políticos de um Estado" e cidadania "tem que ver com a condição de cidadão, quer dizer, com o uso dos direitos e o direito de ter deveres de cidadão" (FREIRE, 2001, p. 25). É assim que ele 
entende "a alfabetização como formação da cidadania" e como "formadora da cidadania" (Ibidem).

Nesse sentido, para Freire (1996, p. 14):

\begin{abstract}
formar é muito mais do que puramente treinar o educando no desempenho de destrezas, e porque não dizer também da quase obstinação com que falo de meu interesse por tudo o que diz respeito aos homens e às mulheres, assunto de que saio e a que volto com o gosto de quem a ele se dá pela primeira vez. Daí a crítica permanentemente presente em mim à malvadez neoliberal, ao cinismo de sua ideologia fatalista e a sua recusa inflexível ao sonho e à utopia.
\end{abstract}

No livro Pedagogia da Autonomia especialmente Freire lista alguns saberes necessários a prática educativa progressista, a saber: Ensinar exige rigorosidade metódica, pesquisa, respeito aos saberes dos educandos, criticidade, estética e ética, corporeificação das palavras pelo exemplo, risco, aceitação do novo e rejeição a qualquer forma de discriminação, reflexão crítica sobre a prática, reconhecimento e a assunção da identidade cultural, consciência do inacabamento, reconhecimento de ser condicionado, respeito a autonomia do ser do educando, bom-senso, humildade, tolerância e luta em defesa dos direitos dos educadores, apreensão da realidade, alegria e esperança, convicção de que a mudança é possível, curiosidade, segurança, competência profissional e generosidade, comprometimento, compreender que a educação é uma forma de intervenção no mundo, liberdade e autoridade, tomada consciente de decisões, saber escutar, reconhecer que a educação é ideológica, disponibilidade para o diálogo, querer bem os educandos. Todos esses elementos, são indispensáveis para pensar a formação do cidadão contemporâneo, enquanto sujeito comprometido com a construção da realidade social, cultural, política, econômica, etc.

Assim que, formar o cidadão, com vistas ao desenvolvimento de sua consciência crítica, é oferecer meios intelectuais para o desvelamento dos processos sociais, políticos, econômicos, culturais e espaciais. Tal perspectiva de formação é uma condição indispensável para o desenvolvimento da consciência social e política, para pensar a sociedade e criar possibilidades de participar da história como sujeito. Conforme Freire (1994, p. 830), “diminuir a distância entre o discurso e a prática é o que se denomina coerência". Assim que, aprender utilizar-se da prática e da teoria, é buscar novas formas de sociabilidade, com o verdadeiro exercício da cidadania.

Tal práxis educativa se apresenta como um processo de "hominização", em contraposição ao atual modelo de formação calcado nas atuais relações econômicas, que se resultam na alienação do homem e na expropriação de seu saber. Para tanto, há

\begin{tabular}{|l|l|l|l|l|} 
Revista Dialectus & Ano 1 & n. 2 & Janeiro-Junho 2013 & p. 195-210 \\
\hline
\end{tabular}


necessidade de uma ética universal do ser humano e de marchas em favor dos direitos humanos, marchas para a efetivação da democracia radical.

Concorda-se com Herbert ao explicitar o significado de cidadania na perspectiva de Paulo Freire, que

a cidadania se manifesta por meio das relações sociais, por meio do exercício de produzir coletividade e poder relacionamentos continuados em favor da vivência dos direitos e deveres dos indivíduos nos grupos sociais. Um relacionamento compartilhado e participativo é condição necessária para o exercício da cidadania (HERBERT, 2010, p. 67).

A cidadania é um processo construído culturalmente e historicamente, "ela começa na relação que a pessoa faz consigo mesma e depois vai expandindo-se para o outro e para a sociedade" (THOMAZ, 2008, p. 34). De tal modo que, formar o cidadão na perspectiva freireana, implica necessariamente, incentivar a leitura critica do mundo, capaz de permitir que os educandos tomem consciência do movimento dialético da realidade em que estão inseridos, reconhecendo-nos que "somos seres condicionados mas não determinados". O que significa conceber a história como tempo de possibilidade, como problematização do presente e a esperança na construção de um futuro menos injusto, mais humano.

Do mesmo modo, Santos considera o cidadão como "multidimensional. Cada dimensão se articula com as demais na procura de um sentido para a vida. Isso é que dele faz um indivíduo em busca do futuro, a partir de uma concepção de mundo" (SANTOS, 2002, p. 42). O cidadão é aquele indivíduo que se reconhece como sujeito, como ser histórico, transformador e solidário, isto é, que para tornar-se agente ativo do processo histórico, tem de assumir-se enquanto sujeito, responsabilizar pelas transformações e colocar-se a serviço da coletividade e do bem comum. Assim, o cidadão é aquele sujeito "que tem a capacidade de entender o mundo, a sua situação no mundo e de compreender os seus direitos para poder reivindicá-los" (SANTOS, 1997, p. 133). Milton Santos apostava numa leitura critica do espaço como ferramenta essencial ao processo de desalienação e como indispensável para constituição de um espaço com cidadãos. Assim destacava

a luta pela cidadania não se esgota na confecção de uma lei ou da Constituição porque a lei é apenas uma concreção, um momento finito de um debate filosófico sempre inacabado. Assim como o indivíduo deve estar sempre vigiando a si mesmo para não se enredar pela alienação circundante, assim o cidadão, a partir das conquistas obtidas, tem de permanecer alerta para garantir e ampliar sua cidadania. (SANTOS, 2002, p. 80) 
Nesses termos, na visão de Santos (2000, p. 55), "nossa grande tarefa, hoje, é a elaboração de um novo discurso, capaz de desmistificar a competitividade e o consumo e de atenuar, senão desmanchar, a confusão de espíritos". Ou seja, Santos aponta para a necessidade do desenvolvimento de processo de ensino e aprendizagem, cuja pedagogia conduza ao desvelamento da realidade, daí vai ao encontro do pensamento de Freire. Como salienta Silva (2008, p. 7): "aprendendo a ler as artimanhas de dominação fica bem mais fácil impor força ao espírito e resistir às tentações do mundo da produção. Também podemos entender isso como nitidez política do contexto em que vivemos." Tal nitidez é possível mediante análise rigorosa dos acontecimentos.

Concorda-se com Silva (2008, p. 1) que

\begin{abstract}
ambos proporcionam raciocínios que permitem desvelar vários processos da realidade social e política do contexto histórico social brasileiro. Com eles é possível pensar o mundo levando em consideração as diversas dimensões da historicidade, refletir sobre o espaço e o tempo de forma compreensiva e entender os complexos das práticas sociais mais ampliados. A partir de suas mundividências é possível conhecer, repensar e criar novos conceitos. Para eles a realidade é consequência de ações de homens e mulheres durante o processo histórico. Ela não algo natural, mas criada sócioculturalmente.
\end{abstract}

Freire e Santos nos oferecem ferramentas conceituais indispensáveis para a formação do cidadão. Considerando que a cidadania trata-se de uma construção que acontece a partir da práxis e da participação política, é fundamental um ensino comprometido com a formação do sujeito historicamente situado. Tal como o consumo, que se trata de um processo de 'invasão cultural' ${ }^{3}$, resultado também de um aprendizado, acredita-se que através da leitura crítica da realidade, é possível desenvolver um processo de "síntese cultural" de que fala Freire, e assim construir outras formas de sociabilidade a partir da práxis homens e mulheres no processo de construção da história. Considerando que,

o homem é um ser da práxis, da ação e reflexão. Nestas relações com o mundo, através de sua ação sobre ele, o homem se encontra marcado pelos resultados de sua própria ação. Atuando, transforma; transformando, cria uma realidade que, por sua vez, envolve-o, condiciona sua forma de atuar (FREIRE, 1992, p. 28).

O mundo será o que, enquanto sujeitos históricos nós responsabilizarmos e comprometermos em fazer hoje. A consciência da historicidade, da realidade e da

\footnotetext{
${ }^{3}$ Para Freire (1987, p. 180): “A invasão cultural, os espectadores e a realidade, que deve ser mantida como está, são a incidência da ação dos atores. Na síntese cultural, onde não há espectadores, a realidade a ser transformada para a libertação dos homens é a incidência da ação dos atores. Isto implica que a síntese cultural é a modalidade de ação com que, culturalmente, se fará frente à força da própria cultura, enquanto mantenedora das estruturas em que se forma."
}

\begin{tabular}{|l|l|l|l|l|} 
Revista Dialectus & Ano 1 & n. 2 & Janeiro-Junho 2013 & p. 195-210 \\
\hline
\end{tabular}


cultura enquanto resultado de nossas ações, é fundamental para que as transformações sociais, educacionais, políticas, econômicas, culturais, ambientais aconteçam.

\section{Considerações Finais}

Freire e Santos em seus diversos escritos pensam a sociedade, o ser humano, a educação, numa mesma direção. Ambos comprometeram-se em encontrar meios para pensar a formação dos sujeitos, a fim de desenvolver análise crítica de sua própria condição. Apostavam na construção de uma sociedade menos desigual, no entanto, salientava a necessidade de uma educação como instrumento de emancipação, pois, o mais grave da sociedade vigente, além do consumo, da cultura de massas, da cidadania regulada, é que a maioria da população é desprovida dos meios para análise crítica da realidade.

Para tanto, afirmavam a necessidade de uma formação em que o ser humano elevase a condição de sujeito e comprometesse com seu tempo. Eles acreditaram na capacidade humana de construir o mundo, fazer história e cultura baseada em princípios éticos. Eles romperam com fatalismo histórico, com a concepção de neutralidade da ciência, da educação. Ao contrário, apontam que toda prática é carregada de intencionalidade e finalidades, desconstruindo os discursos dominantes. Os dois trabalharam preocupados e comprometidos com a humanização dos modos de vida, denunciaram processos de desumanização e de opressão, ao mesmo tempo, apontaram possibilidades da construção de novas formas de sociabilidade.

Acreditavam na ampliação da cidadania, a partir da formação do cidadão, não na perspectiva capitalista de cidadão-consumidor, mas do cidadão, sujeito historicamente situado e engajado social e politicamente na transformação de situações opressoras e desumanizantes. De modo que, uma das grandes tarefas do ensino público é contribuir para o reaprendizado da cidadania, "essa pedagogia será mais difícil em certos países" (SANTOS, 2002, p. 125), eis a tarefa dos educadores brasileiros, recuperarem as pedagogias emancipatórias, que tem como centralidade a formação do sujeito consciente, tomando como importante elemento no processo de emancipação do sujeito, a cultura local e o espaço vivido. 


\section{Referências Bibliográficas}

BEZERRA, Aída. A questão política da educação popular. Brasiliense, 1980.

COVRE, Maria de Lourdes Manzini (org.). A cidadania que não Temos. São Paulo: Brasiliense, 1986.

DIMENSTEIN, Gilberto. O cidadão de papel. 16. ed. Sao Paulo: Atica. 1999.

FREIRE, Paulo. Pedagogia do Oprimido. Rio de janeiro, Paz e Terra, 1987.

. Política e Educação. São Paulo: Cortez, 2001.

. Ação Cultural para a liberdade e outros escritos. $3^{\text {a }}$ Ed. Rio de Janeiro, Paz e Terra, 1978.

Pedagogia da autonomia: saberes necessários à prática educativa.

Rio de Janeiro: Paz e Terra, 1996.

. Extensão ou comunicação? 10. ed. Rio de Janeiro: Paz e Terra, 1992.

; MACEDO, Donaldo. Alfabetização: leitura do mundo leitura da

palavra. 2. ed. Rio de janeiro, Paz e Terra, 1994.

LOPES, Josefa Batista. As lutas sociais operárias e populares no Brasil. II Jornada Internacional de Políticas Públicas - eixo, "Lutas Sociais e Direitos" - realizada pelo Programa de Pós-Graduação em Políticas Públicas da UFMA no período de 23 a 26 de agosto de 2005. Visualizado em http://www.joinpp.ufma.br/jornadas/joinppII/pagina_PGPP/Trabalhos2/Josefa_batista_1 opes155.pdf . Acesso em 20 de Fevereiro de 2013.

REZENDE FILHO, Cyro de Barros; CÂMARA NETO, Isnard de Albuquerque. A evolução do conceito de cidadania. Visualizado em: http://www.unitau.br/scripts/prppg/humanas/download/aevolucao-N2-2001.pdf. Acesso em 20 de Fevereiro de 2013.

SANTOS, Milton. Por uma outra globalização: do pensamento único à consciência universal. Rio de Janeiro: Record, 2000.

O espaço do cidadão. São Paulo: Nobel, 2002.

. As Cidadanias Mutiladas. In: Preconceito. São Paulo: Secretaria da Justiça e da defesa da Cidadania do Estado de São Paulo, 1997.

SANTOS, Wanderley Guilherme. Cidadania e Justiça. Rio de Janeiro: Editora Campus, 1979.

\begin{tabular}{|l|l|l|l|l|} 
Revista Dialectus & Ano 1 & n. 2 & Janeiro-Junho 2013 & p. 195-210 \\
\hline
\end{tabular}


SILVA, Luiz Etevaldo. Paulo Freire e Milton Santos: Um encontro em favor da cidadania e da solidariedade. In: Revista e-Curriculum, PUCSP - SP, Volume 3, número 2, junho de 2008. Disponível em: http:/www.pucsp.br/ecurrculum

THOMAZ, Lourdes. Os caminhos da cidadania. Material Didático elaborado para definir diretrizes de ação do Programa de Desenvolvimento Educacional - PDE Secretaria de Estado da Educação do Paraná. Ponta Grossa/PR, 2008. Visualizado em: http://www.diaadiaeducacao.pr.gov.br/portals/pde/arquivos/1709-6.pdf Acesso em 20 de Fevereiro de 2013. 